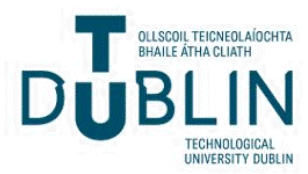

Technological University Dublin

ARROW@TU Dublin

\section{Effect of cold plasma treatment on the antigenicity of peanut allergen Ara h 1}

\author{
Harshitha Venkataratnam \\ Technological University Dublin, harshitha.venkataratnam@tudublin.ie \\ Chaitanya Sarangapani \\ Technological University Dublin, chaitanyakrishna.sarangapani@tudublin.ie \\ Orla Cahill \\ Technological University Dublin, orla.cahill@tudublin.ie
}

See next page for additional authors

Follow this and additional works at: https://arrow.tudublin.ie/schfsehart

Part of the Food Chemistry Commons

\section{Recommended Citation \\ This Article is brought to you for free and open access by the School of Food Science and Environmental Health at ARROW@TU Dublin. It has been accepted for inclusion in Articles by an authorized administrator of ARROW@TU \\ Dublin. For more information, please contact \\ arrow.admin@tudublin.ie, aisling.coyne@tudublin.ie, gerard.connolly@tudublin.ie. \\ Funder: Technological University Dublin}

Harshitha Venkataratnam, Chaitanya Sarangapani, Orla Cahill, Catherine Barry Ryan, Effect of cold plasma treatment on the antigenicity of peanut allergen Ara $\mathrm{h} 1$, Innovative Food Science \& Emerging Technologies, Volume 52, 2019, Pages 368-375, ISSN 1466-8564, DOI: 10.1016/j.ifset.2019.02.001.

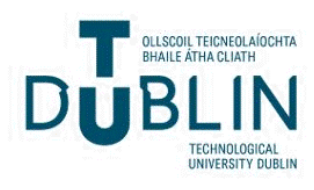


Authors

Harshitha Venkataratnam, Chaitanya Sarangapani, Orla Cahill, and Catherine Barry-Ryan

This article is available at ARROW@TU Dublin: https://arrow.tudublin.ie/schfsehart/437 


\title{
Effect of cold plasma treatment on the antigenicity of peanut allergen Ara $\mathrm{h}$
} 1

\author{
Harshitha Venkataratnam*, Chaitanya Sarangapani, Orla Cahill, Catherine Barry Ryan \\ School of Food Science and Environmental Health, College of Sciences and Health, Technological University Dublin, Cathal Brugha Street, Dublin 1, Ireland
}

\section{A R T I C L E I N F O}

\section{Keywords:}

Ara h 1

Allergenicity

Cold plasma

Secondary structures

\begin{abstract}
A B S T R A C T
The objective of this study was to investigate the effects of cold atmospheric plasma on the antigenicity of protein Ara h 1. Dry, defatted peanut flour (DPF), whole peanut (WP) were subjected to cold atmospheric plasma at voltage of $80 \mathrm{kV}$ for different treatment durations $(0,15,30,45$ and $60 \mathrm{~min})$. The allergen samples were analyzed using SDS-PAGE, immunoblot and competitive ELISA. Furthermore, the secondary structure was examined using circular dichroism. SDS-PAGE results revealed no change in the protein intensity bands corresponding to Ara h 1 for both DPF and WP. Competitive ELISA of samples showed a reduction in antigenicity up to $43 \%$ for DPF and 9.3\% for WP. Circular dichroism studies revealed modifications in secondary structure induced by plasma reactive species.

Industrial relevance: Cold plasma has emerged as a novel processing technique. This study provides evidence for reduction of antigenicity of Ara h1 in peanuts using cold plasma. This study also demonstrated the plasmainduced changes in protein structure at high treatment duration. The work described in this research is relevant to the processing of cereal grains and legumes wherein allergenicity is a major concern. This results provide the basis for possible industrial implementation.
\end{abstract}

\section{Introduction}

Food allergy is considered a major public health concern in both developing and developed countries. It affects nearly $1-2 \%$ of adults and $3-6 \%$ of children in developing countries (Jerschow, Lin, Scaperotti, \& McGinn, 2014). Food allergy is an allergic reaction or abnormal immunological response that occurs when certain foods are consumed (Chizoba Ekezie, Cheng, \& Sun, 2018). Food allergy results from an adverse immunoglobin $\mathrm{E}$ (IgE) mediated (type 1) reaction towards antigens, which are mostly proteins (Jerschow et al., 2014; Johnson et al., 2010). The region on an antigen to which an antibody binds is called an epitope, and they are classified into linear and conformational epitopes (Meinlschmidt et al., 2016). Any food is capable of triggering an allergic reaction; however, eight main protein sources are found to trigger $90 \%$ of all allergic reaction. These are comprised of milk, eggs, peanuts, tree nuts, crustacean/shellfish, wheat and soy (Meinlschmidt et al., 2016; Pfeifer et al., 2015; Piersma, Gaspari, Hefle, \& Koppelman, 2005; Vanga, Singh, \& Raghavan, 2017). Of these, peanut allergy is the most prevalent food allergy in United States and in European countries, affecting nearly $1 \%$ of the population (Luo et al., 2013; Pfeifer et al., 2015). Some studies also suggest the prevalence to be much higher, with an estimate of $10 \%$ of children in the United
Kingdom being sensitized to peanuts (Comstock, Maleki, \& Teuber, 2016; Luo et al., 2013; Nesbit et al., 2012). Additionally, the incidence of peanut allergy appears to be increasing in the past decade, contributing to a growing global concern, given the severity of allergic reactions. Since, allergies are mainly triggered by IgE, lowering the allergen levels might be an effective way to reduce the allergenic risk (Vissers et al., 2011). Earlier, several thermal methods were used to reduce the allergenicity. However, few allergens were resistant to thermal processing (Cabanillas, Jappe, \& Novak, 2018; Comstock et al., 2016; Maleki, Schmitt, Galeano, \& Hurlburt, 2014). Generally, food allergens belong to a particular group of protein families. These comprise the cupin family (7S and 11S seed storage proteins) including vicilins and legumins, the prolamines family characterized by $2 S$ albumins and plant-defense proteins including proteases and protease inhibitors (Zhuang \& Dreskin, 2013). To date, 16 peanut allergens have been identified of which Ara h 2 and Ara h 6 were most frequently sensitized followed by Ara h 1, Ara h 3 and Ara h 7 (Cabanillas et al., 2018). Out of these five major allergens Ara h 2, Ara h 6 and Ara h 7 belong to the family of the $2 \mathrm{~S}$ albumin storage proteins with a molecular weight between 14 and $20 \mathrm{kDa}$. Ara h 6 show 55\% amino acid sequence homology to Ara h 2 where Ara h 7 shows 40\% (Vissers et al., 2011). Similarly, Ara h 1 and Ara h 3 belong to the cupin family, studies

\footnotetext{
* Corresponding author.

E-mail address: harshitha.venkataratnam@mydit.ie (H. Venkataratnam).
} 
indicate that Ara h 3 consists of a set of polypeptides with molecular weights ranging from 14 to $45 \mathrm{kDa}$ (Koppelman et al., 2003). Ara h 1 is a glycosylated, seed-storage protein similar to vicilin in legumes. Ara $\mathrm{h}$ 1 has a molecular weight of $63.5 \mathrm{kDa}$. The subunits of Ara $\mathrm{h} 1$ naturally assemble into trimers $(\sim 180 \mathrm{kDa})$ and aggregate to form multimers ( $\sim 600-700 \mathrm{kDa})$ (Nesbit et al., 2012; Vissers et al., 2011). It has been found to have 23 linear epitopes mainly in the areas of the inter-subunit contact which are protected from protease degradation (van Boxtel, van Beers, Koppelman, van den Broek, \& Gruppen, 2006). Subsequently, changes in these characteristics may result in changes in allergenicity which include changes in epitope structure, epitope accessibility, and protein digestibility (Besler, Steinhart, \& Paschke, 2001). Therefore, there is a need to investigate allergens in their natural form, as particular differences in characteristics may result in incorrect conclusions about their allergenic activity (van Boxtel et al., 2006).

Foods, including peanuts, are subjected to a wide range of processing methods to improve their quality, sensory attributes and shelf-life (Vanga et al., 2017). During processing food proteins undergo modifications like protein-unfolding, aggregation and chemical modification. The changes in structural and chemical properties of the protein itself depend on the type of thermal processing and the operating conditions applied (temperature, $\mathrm{pH}$, and time) (Poms, Capelletti, \& Anklam, 2004). For instance, roasting has been shown to increase the allergenicity of Ara h 1 while boiling has been shown to decrease it (Beyer et al., 2001). However, thermal processing methods can provoke losses in organoleptic quality, nutritional profile or even techno-functionality (Chizoba Ekezie et al., 2018). Consequently, researchers are in search for non-thermal technologies to reduce food allergens without affecting the nutritional quality. Different non-thermal processing methods such as pulsed light, pulsed electric field, high pressure processing (Johnson et al., 2010), irradiation (Luo et al., 2013), ultrasound (Li, Lin, Cao, \& Jameel, 2006) and cold plasma can induce changes in protein conformation and reduce the allergenicity of certain proteins, while retaining nutritive value of food materials (Chizoba Ekezie et al., 2018). Recently, cold plasma processing has emerged as a novel processing method for improving the quality and shelf-life of food (Misra, Schlüter, Cullen, \& Patrick, 2016). Plasma is a partially or wholly ionized state of a gas. Cold plasma generated using a dielectric barrier discharge (DBD) set-up has been widely employed for application of food systems. As a novel technology, plasma oxidation provides several advantages with the production of oxidizing species and radicals $(\mathrm{O} \cdot$, $\cdot$ $\mathrm{OH}, \mathrm{N} \cdot, \mathrm{HO}_{2} \cdot, \mathrm{N}_{2}{ }^{*}, \mathrm{~N}^{*}, \mathrm{OH}^{-}, \mathrm{O}_{2}{ }^{-}, \mathrm{O}^{-}, \mathrm{O}_{2}{ }^{+}, \mathrm{N}_{2}{ }^{+}, \mathrm{N}^{+}, \mathrm{NO}, \mathrm{O}^{+}, \mathrm{O}_{3}$ and $\mathrm{H}_{2} \mathrm{O}_{2}$ ) and other physical effects including UV light, shock waves and cavitation (Sarangapani et al., 2017). However, very few studies have reported the effects of cold plasma on food allergens (Sarangapani, Patange, Bourke, Keener, \& Cullen, 2018). Several authors have investigated the application of non-thermal plasma for microbial decontamination (Ziuzina, Patil, Cullen, Keener, \& Bourke, 2014) and its modification of food and packaging surfaces (Thirumdas, Sarangapani, \& Annapure, 2015). Further applications include increase in surface hydrophobicity in biscuits (Misra et al., 2014), modification of flour (Sarangapani et al., 2016), dough rheology and mixing properties (Misra et al., 2015; Pal et al., 2016), enhancement of germination in rice grains (Chen et al., 2016), degradation of mycotoxins and pesticides residues (Devi, Thirumdas, Sarangapani, Deshmukh, \& Annapure, 2017; Sarangapani, O'Toole, Cullen, \& Bourke, 2017). Several authors have reported that plasma reactive species are responsible for such inactivation, and could also modify the structure of allergen proteins (Chauvin, Judée, Yousfi, Vicendo, \& Merbahi, 2017). The amount and nature of these reactive species in plasma reactors is dependent on different input process parameters, such as inducer gas composition $\left(\mathrm{O}_{2}, \mathrm{~N}_{2}\right.$, Ar etc.) gas flow, electrical power applied and electrode shape (Dojčinović et al., 2011). However, the effect of cold plasma on protein structure is not fully understood. The available literature on cold plasma interactions on proteins reveals a change in the protein structure. The loss of secondary structures such as $\alpha$-helical and ordered $\beta$ sheet elements occur on the exposure of enzymes PPO and POD to plasma (Surowsky, Fischer, Schlueter, \& Knorr, 2013). Similarly, Segat et al. (2014) and Attri et al. (2015) reported plasma induced changes in protein structures. However, very little information is known about its effects on allergens. Early reports by Nooji (2011b) and Shriver, Yang, Chung, and Percival (2011) suggest that cold plasma could possibly reduce the food allergenicity. Recently, Meinlschmidt et al. (2016), reported a profound change in soy immunoreactivty after cold plasma treatment. To the best of our knowledge, there is no report or literature available on the reduction in allergenicity of peanuts particularly Ara h1 by cold plasma. Hence, the objective of this study was to investigate the effects of cold plasma on allergenicity of Ara $h 1$.

\section{Materials and methods}

\subsection{Materials}

Raw peanuts were purchased from a local market (Rongs Asian supermarket, Dublin, Ireland). Peanuts were stored at room temperature. All chemicals used in this study were purchased from SigmaAldrich, Dublin Ireland, unless otherwise stated. Peanuts were ground in liquid nitrogen using a mortar and pestle. They were defatted using n-hexane for $5 \mathrm{~h}$ at $4{ }^{\circ} \mathrm{C}$.

\subsection{Plasma treatment}

The experimental apparatus consisted of two aluminum plate electrodes of circular geometry (outer diameter $=158 \mathrm{~mm}$ ) which were covered with a dielectric material of 2-mm thickness for the ground electrode and $10 \mathrm{~mm}$ thick acrylic sheet for the high voltage electrode (Fig. 1). For each experiment, $10 \mathrm{~g}$ of each deshelled whole peanut with skin (WP) and defatted peanut flour (DPF) were added to a petri dish separately and $5 \mathrm{~mm}$ sample depth was maintained. These petri dishes were placed within a polypropylene container of dimensions $310 \mathrm{~mm} \times 230 \mathrm{~mm} \times 22 \mathrm{~mm}$ which acts as a closed reactor and as an additional dielectric barrier. The relative humidity in the box was maintained at $80 \%$ by passing the working gas through a water bubbler with specific flow rate and water depth, the resultant humidity was measured with a psychrometer. This container was further sealed inside a high-barrier Cryovac BB3050 film in order to prevent loss of reactive species generated during plasma treatment. The voltage was delivered through a step-up transformer (Phenix Technologies, Inc., California, USA) whose primary winding received input at $230 \mathrm{~V}, 50 \mathrm{~Hz}$ and delivered a high voltage output in the range $0-120 \mathrm{kV}$ and the air was used as discharge gas. Plasma treatment was performed at a voltage of $80 \mathrm{kV}$ and treatment durations $(0-60 \mathrm{~min})$ maintained. After processing, containers were stored at room temperature of $16-18{ }^{\circ} \mathrm{C}$ for $24 \mathrm{~h}$ in line with previous findings that sealed retention time is useful for biocontrol (Ziuzina et al., 2014). This allows contact time of the generated chemical reactive species to be contained with the samples. Control samples were not subjected to plasma-treated.

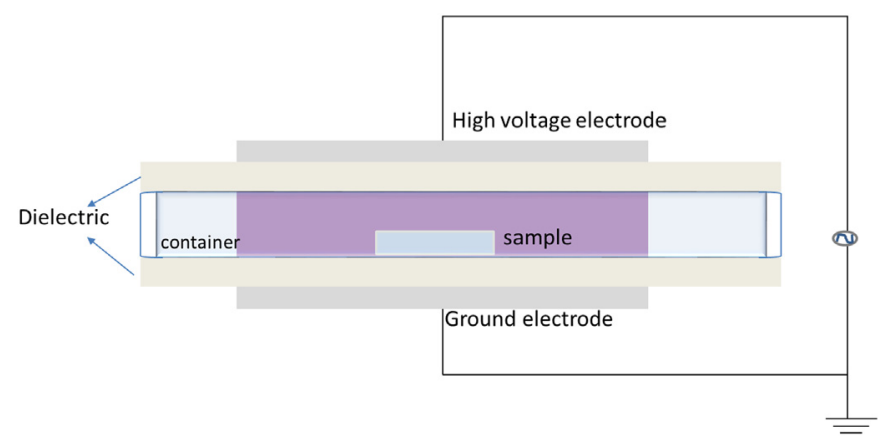

Fig. 1. Schematic diagram of the cold plasma experimental setup. 


\subsection{Extraction and purification}

Extraction and purification of Ara $\mathrm{h} 1$ were performed using the procedures of Maleki et al. (2000) with slight modifications. Briefly, defatted peanut was extracted using extraction buffer $(50 \mathrm{mM}$ Tris, $200 \mathrm{mM} \mathrm{NaCl}$, and $1 \mathrm{mM}$ EDTA at $\mathrm{pH} 8.3$ ) for $2 \mathrm{~h}$ at $4{ }^{\circ} \mathrm{C}$. The suspension was centrifuged at $12,000 \mathrm{~g}$ for $15 \mathrm{~min}$. The supernatant was subjected to $100 \%$ ammonium sulfate precipitation and protein pellet was collected after centrifugation. The collected protein was resolubilized in buffer at $\mathrm{pH} 8.3$ without $\mathrm{NaCl}$, desalted by dialysis against buffer overnight in the ratio 1:40. This was loaded on to a High Prep Q column and eluted with a linear salt gradient $(50-300 \mathrm{mM} \mathrm{NaCl})$. Fractions were collected and Sodium Dodecyl Sulfate polyacrylamide gel electrophoresis (SDS-PAGE) was run at reducing conditions. Protein concentration was checked at every step using Bradford assay.

\subsection{Electrophoresis}

SDS-PAGE was performed using $12 \%$ hand-cast gels (Laemmli, 1970). Proteins were reduced and denatured using sample buffer. Prior to loading, samples were heated at $100{ }^{\circ} \mathrm{C}$, for 10 min. Prestained molecular marker (Fisher Scientific, Dublin, Ireland) were used as a reference. Electrophoresis was performed at a constant voltage of $150 \mathrm{~V}$ in Tris glycine buffer. Rapid staining was performed according to Studier (2005). Briefly, gel is suspended in approximately $50 \mathrm{~mL}$ of $50 \%$ ethanol, $10 \%$ acetic acid and $40 \%$ water, heated to almost boiling in a microwave oven and rocked on a shaker until the gel shrinks. The liquid is discarded and suspended in $50 \mathrm{~mL}$ of $5 \%$ ethanol, $7.5 \%$ acetic acid and $0.25 \%$ coomassie blue in ethanol. The gel is again heated to boiling in a microwave and placed on a rocker. The gels were visualized within $30 \mathrm{~min}$.

\subsection{Immunoblotting}

SDS-PAGE gels were prepared under reducing conditions, as described in Section 2.4 and the separated proteins were transferred to nitrocellulose membrane at a constant voltage of $20 \mathrm{~V}$ for $2 \mathrm{~h}$. The membrane was blocked with $5 \%$ skim milk in phosphate-buffer saline containing $2 \%$ Tween 20 (PBST) for $2 \mathrm{~h}$ at room temperature, followed by overnight incubation with rabbit anti-Ara h 1 (1:5000 in PBST, Indoor Biotechnologies) at $4{ }^{\circ} \mathrm{C}$. Then the membrane was washed thrice using phosphate-buffer saline (PBS), followed by incubation with goat anti-rabbit conjugated with horseradish peroxidase (HRP) (1:5000, Thermo Fischer Scientific, Dublin, Ireland) for $2 \mathrm{~h}$ at room temperature. After further washing, images were developed by incubating with an enhanced chemiluminescent luminol substrate for $1 \mathrm{~min}$ and observed on C-diGit blot scanner (LI-COR).

\subsection{Competitive enzyme linked immune sorbent assay (ELISA)}

The IgG-binding abilities of cold plasma-treated WP and DPF Ara $\mathrm{h}$ 1 were tested using competitive ELISA. The 96-well microtitre plates were coated with $100 \mu \mathrm{L}$ of purified native Ara h $1(0.1 \mu \mathrm{g} / \mathrm{mL})$ in coating buffer $\left(0.1 \mathrm{M} \mathrm{NaHCO}_{3}, \mathrm{pH} 9.6\right)$ and incubated overnight at $4{ }^{\circ} \mathrm{C}$. The wells were washed with phosphate-buffer saline twin 20 (PBST) thrice and later blocked with $3 \%$ bovine serum albumin in PBST for $2 \mathrm{~h}$ at $37^{\circ} \mathrm{C}$. Samples were mixed with equal volumes of rabbit Anti-Ara h 1 (1:5000) and incubated for $30 \mathrm{~min}$ at $37^{\circ} \mathrm{C}$. This mixture was added onto the coated plates and further incubated for $1 \mathrm{~h}$ at $37^{\circ} \mathrm{C}$. After further washing, $100 \mu \mathrm{L}$ of goat anti-rabbit conjugated with HRP (1:4000) were then added to each well, followed by incubation for $1 \mathrm{~h}$ at $37^{\circ} \mathrm{C}$ for detection of bound immunogen. The plates were further washed, and the colour was developed by adding $100 \mu \mathrm{L}$ of $3,3^{\prime}, 5,5^{\prime}$ tetramethylbenzidine to each well and incubated for $15 \mathrm{~min}$ at room temperature. The reaction was terminated using $100 \mu \mathrm{L}$ of $1 \mathrm{~N}$ hydrochloric acid and the absorbance of processed and unprocessed samples were read at $450 \mathrm{~nm}$ with a plate reader.

\subsection{Secondary structure determination}

Conformational changes in the secondary structure were determined using Far UV (190-240 nm) circular dichroism (CD) spectra. Protein concentration was $0.1 \mathrm{mg} / \mathrm{mL}$ and spectra was obtained at room temperature with a JASON Model J-810 spectropolarimeter using a 1$\mathrm{mm}$ path length quartz cell, at a rate of $100 \mathrm{~nm} / \mathrm{min}$ and bathwidth of $1.0 \mathrm{~nm}$. Cold plasma-treated and native Ara h 1 are desalted using centrifugal filters into Milli-Q water and immediately used in CD measurements. A CD spectrum of Milli-Q water was obtained for background purpose and subtracted from each spectra. The secondary structure composition was calculated by Dichroweb server (program: CDSSTR; reference set: SET 7 optimized for 190-240 nm).

\subsection{Statistical analysis}

Statistical analysis was performed using SPSS software (IBM statistical analysis Version 19), and the results were statistically analyzed by one-way ANOVA. The significance among the samples was compared at $\mathrm{P}<0.05$ by the least significant difference post-hoc comparison. All the tests were performed in duplicate and the average of the tests are represented.

\section{Results and discussion}

\subsection{SDS-PAGE}

SDS-PAGE analysis of cold atmospheric plasma-treated WP and DPF under reducing conditions is shown in Fig. 2(a and b). After extraction of the total soluble protein content of plasma-treated DPF and WP, $2 \mathrm{mg} / \mathrm{mL}$ of each are loaded on the gels. Analysis demonstrated no notable change in the protein profile of both WP and DPF when compared to control. The band at $63.5 \mathrm{kDa}$, which corresponds to the major allergen Ara h 1, both WP and DPF showed no change on the gel even with increased treatment time. This suggests that plasma exposure did not have any adverse effect on Ara $\mathrm{h} 1$ and that the total protein degradation was likely to be very small. A similar investigation targeted at the major milk allergen $\alpha$-casein showed no significant change in the SDS-PAGE band intensity when compared to the untreated (Tammineedi, Choudhary, Perez-Alvarado, \& Watson, 2013). Furthermore, studies by Pal et al. (2016) found similar results with no change in the protein profile of plasma-treated rice storage proteins. This could be attributed to changes observed in polysaccharides characteristics. On the contrary, studies on Gly m5, a major soy allergen, which has structural similarity with Ara h 1 showed a decrease in the band intensity after plasma treatment (Meinlschmidt et al., 2016). This decrease in band intensity could be attributed to interactions between plasma active species and protein. Previous studies report that plasma active plasma species such as ozone promotes the oxidation of proteins resulting in disulfide bond formation (Uzun, Ibanoglu, Catal, \& Ibanoglu, 2012). However, such effects were not observed in the present study.

\subsection{Immunoblotting}

The immunoblot of both WP and DPF after cold plasma treatment $(15,30,45$ and $60 \mathrm{~min})$ is shown in Fig. 3. Fig. 3(a) and (b) demonstrated that plasma treatment affected the IgE binding activity of Ara $\mathrm{h}$ 1. Band intensity of Ara h 1 decreased with increase in treatment time for both WP and DPF when compared to the control. As shown in Fig. 3 the immunoblot of samples treated at $80 \mathrm{kV}$ showed a decrease in IgE binding reactivity after $30 \mathrm{~min}$ exposure (Lane 3 ). The components of peanuts such as protein and lipids may prevent the IgE binding of Ara $h$ 1 at short doses, however, increase in plasma doses might alter the 
a)

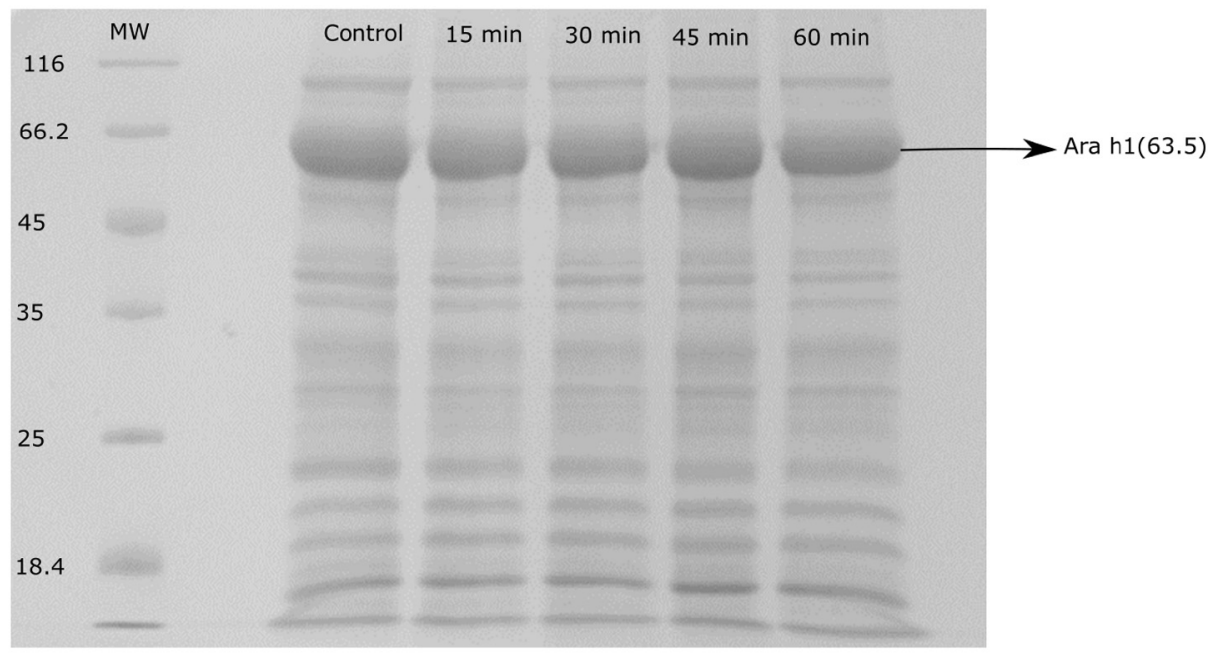

b)

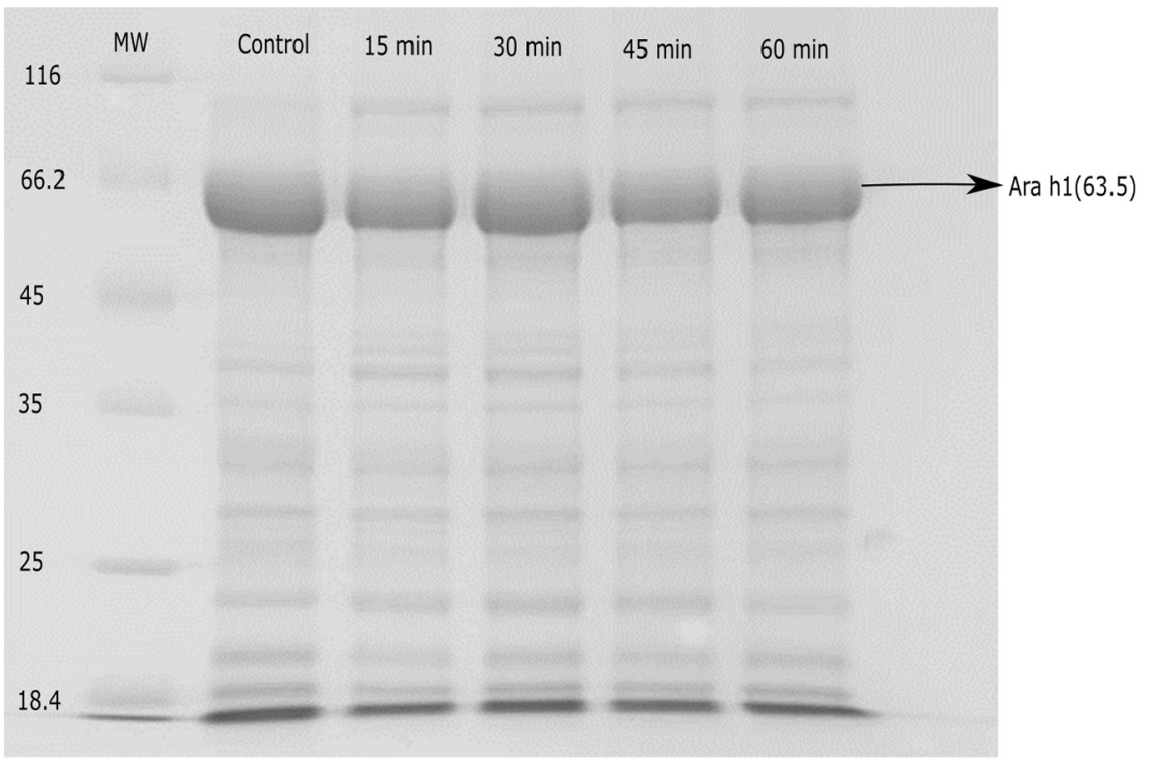

Fig. 2. SDS-Pattern of cold plasma-treated DPF (a) and WP (b) at various treatment duration.

functionality of protein-lipid complex (Lii, Liao, Stobinski, \& Tomasik, 2002). In the present study cold plasma treatment of DPF and WP did not appear to cause any intramolecular cross-linking or band smearing when probed with Anti-Ara h 1. It was observed that after $60 \mathrm{~min}$ of plasma treatment, the IgE binding patterns of DPF showed low band intensity when compared to WP. Similar reduction in IgE binding was observed in cold plasma-treated wheat protein extracts (Nooji, 2011a). These authors also indicated a decrease in IgE binding depends on treatment time. This reduction is due to the active species such as $\mathrm{O} \cdot$, · $\mathrm{OH}, \mathrm{N} \cdot, \mathrm{HO}_{2} \cdot \mathrm{N}_{2}{ }^{*}, \mathrm{~N}^{*}, \mathrm{OH}^{-}, \mathrm{O}_{2}{ }^{-}, \mathrm{O}^{-}, \mathrm{O}_{2}{ }^{+}, \mathrm{N}_{2}{ }^{+}, \mathrm{N}^{+}$, and $\mathrm{O}^{+}$generated during plasma treatment could easily penetrate the DPF sample (increased surface area due to grinding) compared to WP (Sarangapani, Danaher, et al., 2017). A decrease in the IgE binding pattern is due to the generation of free radicals during plasma treatment which could disrupt or mask the binding epitope (Sarangapani et al., 2018). Results from this study are in accordance with Zhenxing, Hong, Limin, and Jamil (2007) who reported that components such as lipids in shrimp muscles would help to protect the allergen from damage by free radicals at low irradiation doses. A similar decrease in IgE binding were also observed in cold plasma treatment of shrimp extract (Shriver, 2011).

\subsection{Competitive ELISA}

In this assay, the antigenicity was measured on the basis of inhibition, the higher the inhibition, the more antigenic Ara $h$ 1. For comparison, the antigenicity of cold plasma-treated Ara h 1 from DPF and WP were investigated. The antigenicity of peanut allergen Ara $\mathrm{h} 1$ after various plasma doses is shown in Fig. 4(a) and (b). The results showed that antigenicity of cold plasma-treated peanuts depends on treatment time. The binding levels of DPF showed a gradual decrease with short plasma treatment doses of 15 and $30 \mathrm{~min}$. However, the binding capacity of peanuts treated for 45 and $60 \mathrm{~min}$ showed greater reductions by $20.3 \%$ and $44 \%$ respectively than the control. Similarly, for WP antigenicity decreased by $8.6 \%$ for $45 \mathrm{~min}$ and $9.3 \%$ for $60 \mathrm{~min}$ of plasma treatment compared to the control. These results support the decrease in binding reactivity of Ara h 1 observed on immunoblot. It is already known that cold plasma generates reactive species such reactive oxygen species (ROS) and reactive nitrogen species (RNS), which may 
a)

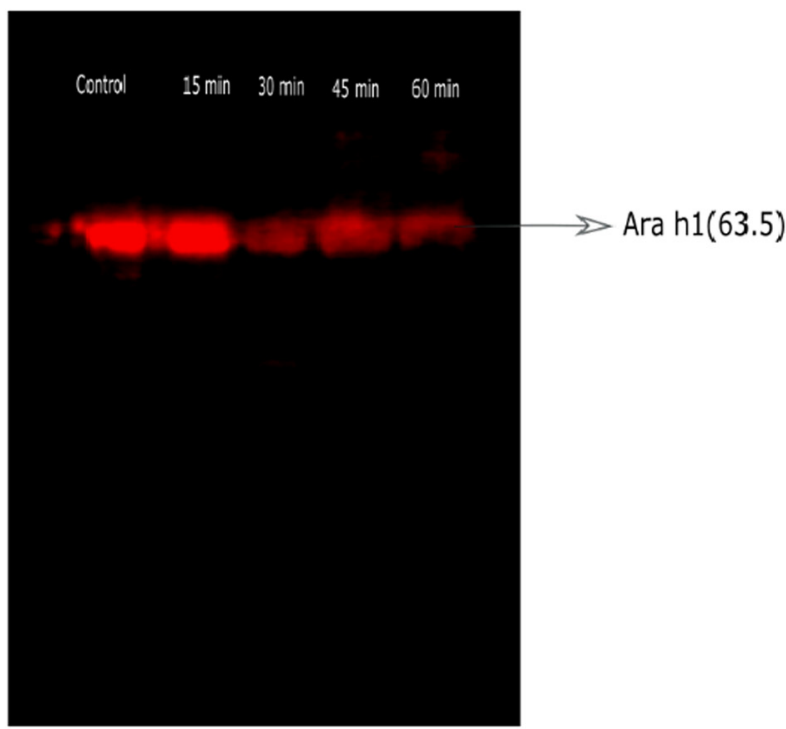

b)

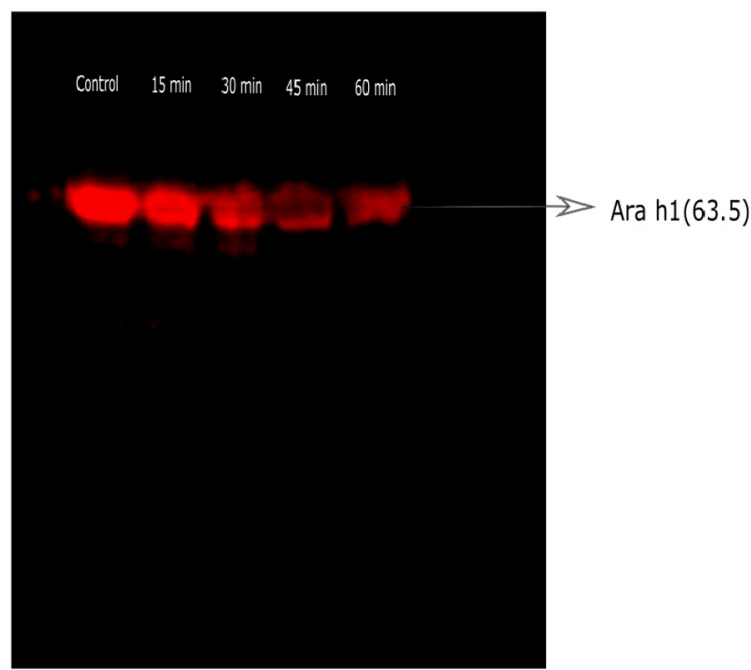

Fig. 3. Immunoblotting of cold plasma-treated Ara h 1 in DPF (a) and WP (b) using anti-Ara h 1 polyclonal antibody.

alter the amino acids, resulting in the change in the binding epitopes (Segat, Misra, Cullen, \& Innocente, 2016). Cold plasma treatment may affect the antigenicity by various mechanisms such as protein denaturation, protein fragmentation, induction of protein conformational modifications (Sarangapani et al., 2018). A similar pattern of results was observed in a recent study on cold plasma treatment of the soy allergen Gly $\mathrm{m}$ 5, where a reduction in binding activity (91-100\%) was reported with direct and remote cold plasma treatment. These authors also reported diminishing of protein in bands due to protein crosslinkage (Meinlschmidt et al., 2016). Similarly, Shriver et al. (2011) used direct cold plasma treatment on shrimp extract and reported the reduction in IgE binding to tropomyosin by up to $76 \%$ when compared to the control. In another study, employing similar conditions Nooji (2011b) reported approximately $25 \%$ reduction in the IgE binding after $3 \mathrm{~min}$ of plasma treatment. Further increase in treatment time to $5 \mathrm{~min}$ resulted in $37 \%$ reduction. These findings explain that higher exposure to plasma has a profound effect on the IgE binding proteins is in agreement with the present study. On the contrary, no significant decrease was observed in the allergenicity of $\alpha$-casein and whey solution by indirect atmospheric plasma treatment. However, the mechanism of cold plasma in reduction of allergenicity has not been fully understood (Tammineedi et al., 2013). Hiramoto et al. (2011) has studied the effect of plasma ions on decrease in antigenicity of mite allergens. These authors reported that reduction of allergenic epitopes on the dust mite allergens is due to generation of hydroxyl radicals by plasma ions. Similarly, Wu et al. (2014) successfully demonstrated the efficacy of the cold plasma against aerosolized allergens both lab-prepared and environmental aerosols. Their results revealed that the mechanism of plasma with allergens depends on the form of protein structure. From these results it can be observed the changes in Ara $\mathrm{h} 1$ binding to IgG and increasing plasma doses could be closely related to the changes in the conformational epitope structures of the proteins.

\subsection{Secondary structure}

The far-UV spectra of Ara h 1 were used to define the extent of secondary structure changes induced by cold plasma at various doses in WP and DPF (Fig. 5). The spectrum of native Ara $\mathrm{h} 1$ exhibited a strong positive peak at $195 \mathrm{~nm}$ with a prominent negative peak at $208 \mathrm{~nm}$ in both WP and DPF. This type of spectrum is characteristic for a protein with a large number of $\alpha$-helical structures (Greenfield, 2006). Fig. 5(a) and (b) shows a progressive decrease in the molar ellipticity at different doses in both DPF and WP, and major changes were observed in the $190-210 \mathrm{~nm}$ region. Ara h 1 in plasma-treated WP, showed a gradual decrease in the intensity of the positive and negative molar ellipticity at $193-197 \mathrm{~nm}$ and $205-210 \mathrm{~nm}$ respectively. A similar decline has been observed for plasma-treated DPF at $193-197 \mathrm{~nm}$ and $205-210 \mathrm{~nm}$. The CD results from this study revealed that the secondary structure of native (untreated) Ara h 1 is composed of $21 \% \alpha$-helix, 16\% turns, $28 \%$ of $\beta$-strands and $35 \%$ of random coil (Fig. 4). All secondary structures for plasma-treated WP samples, exhibited a variation pattern for $\alpha$ helix, $\beta$-strands and turns coils, however, random coil did not display drastic changes (Fig. 4b). The $\alpha$-helix in DPF treated samples declined after 15 min treatment, however, variations were observed in turn, $\beta$ strands and random coils (Fig. 4a). Similar variations in secondary structure has been observed by Meng et al. (2016) in gamma irradiated milk. Surowsky et al. (2013) also observed changes in $\alpha$-helix and $\beta$ strands on exposure to cold plasma treatment of PPO and POD. In another study, Segat et al. (2014) also found loss of $\alpha$-helix and time dependent decrease $\beta$-strands in cold plasma-treated alkaline phosphatase. Attri et al. (2015) reported that the modification in structure depends on the composition of the discharge gas. For instance, when $\mathrm{O}_{2}, \mathrm{~N}_{2}$ and air were used as a discharge major changes were observed in the structure whereas minimal changes were observed with $\mathrm{He}$ and $\mathrm{Ar}$ plasmas.

The mechanism of action of plasma on the allergenicity of proteins has not been completely understood. However, there are multiple known mechanisms that affect protein structure. The major mechanism by which reduction of immunoreactivity is carried out, is by the modification of conformational as well as linear epitopes. This involves a chemical reaction between the protein and the active chemical species of cold plasma causing alteration in protein conformation. The other mechanisms could involve oxidation of amino acids, cleavage of peptide bonds and formation of protein-protein cross linkages. The chemical modifications are caused by hydroxyl radicals $(\cdot \mathrm{OH})$, superoxide anion radicals $\left(\mathrm{O}_{2}\right)$, hydroperoxy radicals $(\mathrm{HOO} \cdot)$ and nitric oxide (NO -) may attack the side chains of amino acids causing loss of its activity (Takai et al., 2014). The plasma active species such as ROS and RNS can cleave the disulfide bonds of the peptide and lead to destruction of binding sites for antibodies. In another study, Pankaj et al. (2014) demonstrated plasma induced changes on the protein based films. These authors suggested that there was formation of more extensive hydrogen bonding between the proteins, leading to the reduction in peptide 

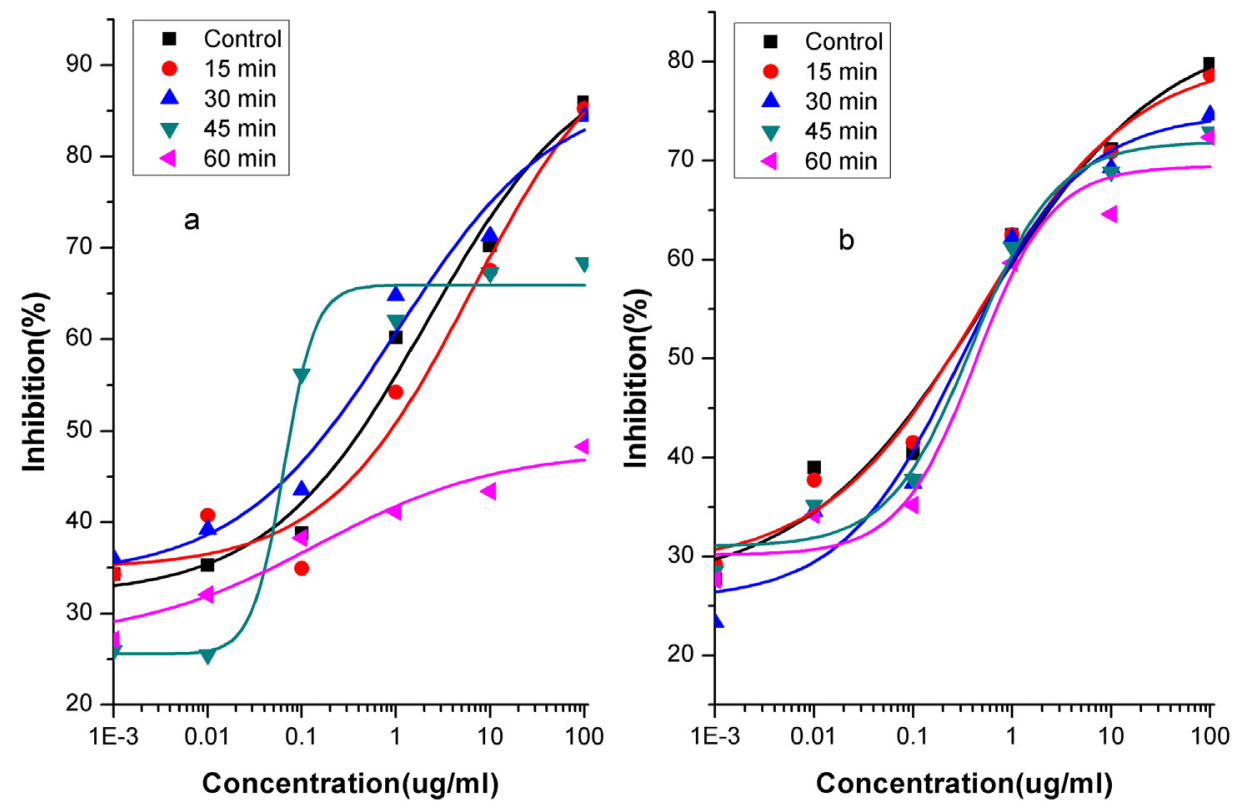

Fig. 4. IgG-binding abilities of cold plasma-treated Ara h 1 in DFP (a) and WP (b) at various treatment times.
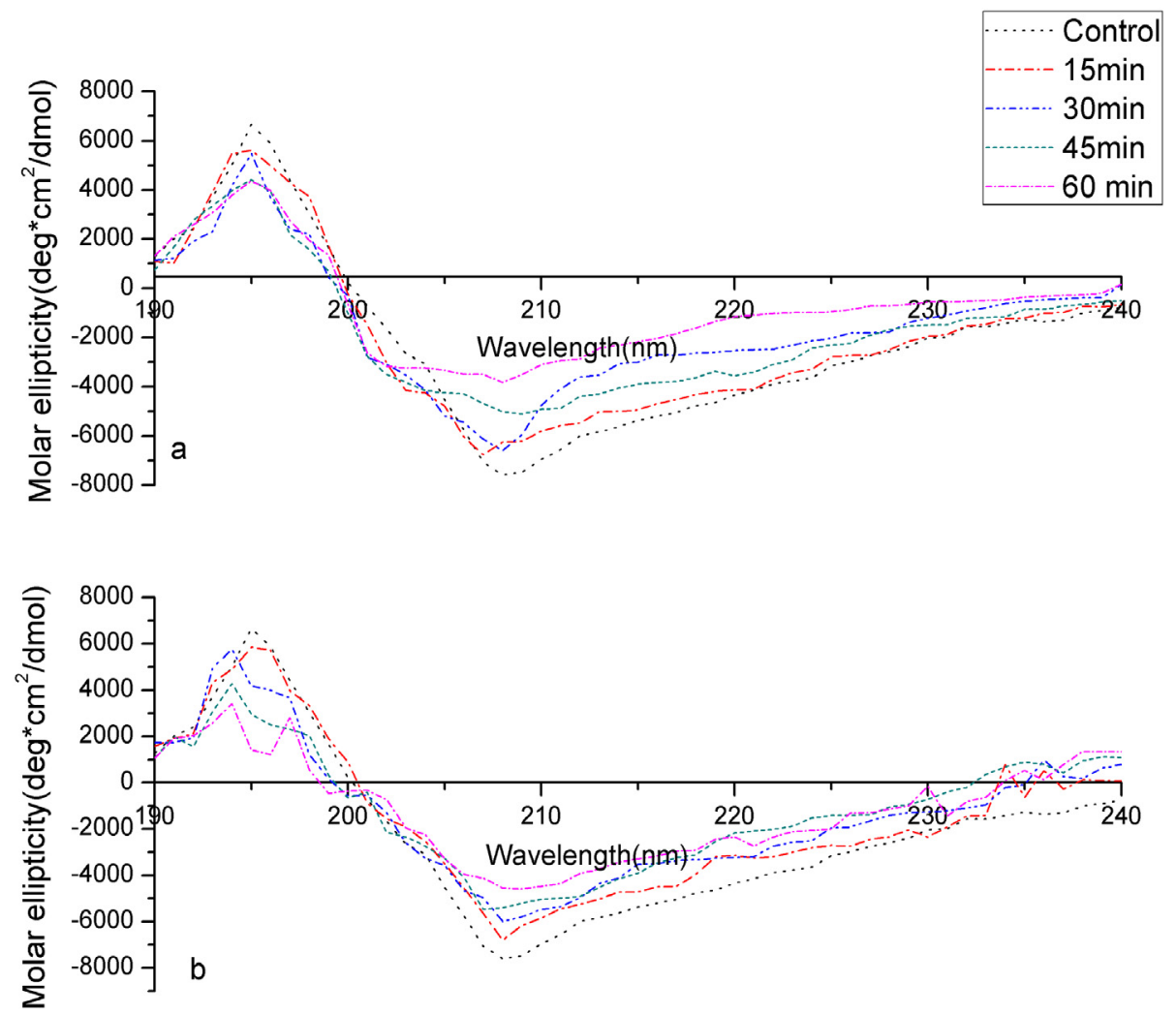

Fig. 5. Circular dichroism of cold plasma-treated Ara h 1 in DPF (a) and WP (b).

linkages and significant effects on protein integrity (Surowsky et al., 2013). These are examples of changes presumably resulting in the destruction of the protein structure.

Besides reduction of allergenicity, cold plasma also improves the techno-functional properties of proteins (Chizoba Ekezie et al., 2018). In a recent study, Bußler, Steins, Ehlbeck, and Schlüter (2015) observed a $113 \%$ and $116 \%$ increase in the water and fat-holding capacities of pea flour after exposure to atmospheric cold plasma for up to $10 \mathrm{~min}$. The authors successfully demonstrated the incidence of conformational alteration, which can be used to describe the observed effects on the techno-functional properties of ACP-treated pea flour fractions. Segat et al. (2014) studied the effect of ACP treatment on whey protein isolate solutions during treatment times ranging from 1 to $60 \mathrm{~min}$. They observed an increase in surface hydrophobicity and foaming stability of WPI due to protein aggregation. This kind of information gives a better understanding of the fundamental interactions and can be used to design plasma systems with appropriate conditions.

CD spectroscopy results provided the possible inactivation mechanisms, which are most likely be changes in $\alpha$-helix structure and $\beta$ sheet content. It is, however, difficult to imagine a mechanism by which 
cold plasma treatment could directly influence the structure of allergenic proteins. From available literature and changes that were observed in this study, it can be suggested that the chemical reactions between protein and reactive species are responsible for alteration. This could involve oxidation of amino acids, cleavage of peptide bonds and formation of protein-protein cross linkages.

\section{Conclusion}

This study determined the efficacy of cold plasma treatment against antigenicity of Ara h1, the major allergen in peanut. The immunoblot and Competitive-ELISA results revealed that cold plasma treatment decreased the antigenicity of Ara h1 in both WP and DPF. However, there were no significant changes observed in SDS-PAGE. It has been observed that reduction in antigenicity depends on treatment time. Additionally, the results from CD spectroscopy provided important insights of cold plasma against Ara h 1 and possible changes in protein structure and allergenicity. Hence, it can also be assumed that similar change in structural and antigenic properties might occur in other peanut allergens. Thus, cold plasma could be a promising alternative approach to reduce peanut allergenicity. Moreover, future studies should be focused on purified allergen proteins to provide important insights into how processing methods affect the allergen. Furthermore, in vivo studies are needed to verify the reduction in allergenicity of cold plasma-treated peanut.

\section{Acknowledgement}

The authors would like to acknowledge the funding from Technological University Dublin, Ireland under Fiosraigh Scholarship programme. Authors would also like to acknowledge Prof. P.J. Cullen for his insight and expertise that greatly assisted the research.

\section{References}

Attri, P., Kumar, N., Park, J. H., Yadav, D. K., Choi, S., Uhm, H. S., ... Lee, W. (2015). Influence of reactive species on the modification of biomolecules generated from the soft plasma. Scientific Reports, 5(1), 8221.

Besler, M., Steinhart, H., \& Paschke, A. (2001). Stability of food allergens and allergenicity of processed foods. Journal of Chromatography B: Biomedical Sciences and Applications, 756(1-2), 207-228.

Beyer, K., Morrowa, E., Li, X.-M., Bardina, L., Bannon, G. A., Burks, A. W., \& Sampson, H. A. (2001). Effects of cooking methods on peanut allergenicity. Journal of Allergy and Clinical Immunology, 107(6), 1077-1081.

Bußler, S., Steins, V., Ehlbeck, J., \& Schlüter, O. (2015). Impact of thermal treatment versus cold atmospheric plasma processing on the techno-functional protein properties from Pisum sativum 'Salamanca'. Journal of Food Engineering, 167, 166-174.

Cabanillas, B., Jappe, U., \& Novak, N. (2018). Allergy to peanut, soybean, and other legumes: recent advances in allergen characterization, stability to processing and IgE cross-reactivity. Molecular Nutrition \& Food Research, 62(1), 1700446.

Chauvin, J., Judée, F., Yousfi, M., Vicendo, P., \& Merbahi, N. (2017). Analysis of reactive oxygen and nitrogen species generated in three liquid media by low temperature helium plasma jet. Scientific Reports, 7(1), 4562.

Chen, H. H., Chang, H. C., Chen, Y. K., Hung, C. L., Lin, S. Y., \& Chen, Y. S. (2016). An improved process for high nutrition of germinated brown rice production: Lowpressure plasma. Food Chemistry, 191, 120-127.

Chizoba Ekezie, F.-G., Cheng, J.-H., \& Sun, D.-W. (2018). Effects of nonthermal food processing technologies on food allergens: A review of recent research advances. Trends in Food Science \& Technology, 74, 12-25.

Comstock, S. S., Maleki, S. J., \& Teuber, S. S. (2016). Boiling and frying peanuts decreases soluble peanut (Arachis Hypogaea) allergens Ara h 1 and Ara h 2 but does not generate hypoallergenic peanuts. PLoS One, 11(6), e0157849.

Devi, Y., Thirumdas, R., Sarangapani, C., Deshmukh, R. R., \& Annapure, U. S. (2017). Influence of cold plasma on fungal growth and aflatoxins production on groundnuts. Food Control, 77, 187-191.

Dojčinović, B. P., Roglić, G. M., Obradović, B. M., Kuraica, M. M., Kostić, M. M., Nešić, J., \& Manojlović, D. D. (2011). Decolorization of reactive textile dyes using water falling film dielectric barrier discharge. Journal of Hazardous Materials, 192(2), 763-771.

Greenfield, N. J. (2006). Using circular dichroism spectra to estimate protein secondary structure. Nature Protocols, 1(6), 2876-2890.

Hiramoto, K., Orita, K., Yamate, Y., Sato, E. F., Okano, H., Nishikawa, K., \& Inoue, M. (2011). Plasma cluster ions decrease the antigenicity of mite allergens and suppress atopic dermatitis in NC/Nga mice. Archives of Dermatological Research, 303(5), 367-370.

Jerschow, E., Lin, R. Y., Scaperotti, M. M., \& McGinn, A. P. (2014). Fatal anaphylaxis in the United States, 1999-2010: Temporal patterns and demographic associations. Journal of Allergy and Clinical Immunology, 134(6), 1318-1328.e7.

Johnson, P. E., Van der Plancken, I., Balasa, A., Husband, F. A., Grauwet, T., Hendrickx, M., ... Mackie, A. R. (2010). High pressure, thermal and pulsed electric-field-induced structural changes in selected food allergens. Molecular Nutrition \& Food Research, 54(12), 1701-1710.

Koppelman, S. J., Knol, E. F., Vlooswijk, R. A. A., Wensing, M., Knulst, A. C., Hefle, S. L., .. Piersma, S. (2003). Peanut allergen Ara h 3: Isolation from peanuts and biochemical characterization. Allergy, 58(11), 1144-1151.

Laemmli, U. K. (1970). Cleavage of structural proteins during the assembly of the head of bacteriophage T4. Nature, 227(5259), 680-685

Li, Z., Lin, H., Cao, L., \& Jameel, K. (2006). Effect of high intensity ultrasound on the allergenicity of shrimp. Journal of Zhejiang University. Science. B, 7(4), 251-256.

Lii, C.y., Liao, C.d., Stobinski, L., \& Tomasik, P. (2002). Exposure of granular starches to low-pressure glow ethylene plasma. European Polymer Journal, 38(8), 1601-1606.

Luo, C., Hu, C., Gao, J., Li, X., Wu, Z., Yang, A., \& Chen, H. (2013). A potential practical approach to reduce Ara h 6 allergenicity by gamma irradiation. Food Chemistry, 136(3-4), 1141-1147.

Maleki, S. J., Kopper, R. A., Shin, D. S., Park, C. W., Compadre, C. M., Sampson, H., Bannon, G. A. (2000). Structure of the major peanut allergen Ara h 1 may protect IgEbinding epitopes from degradation. Journal of Immunology (Baltimore, Md. : 1950), 164(11), 5844-5849.

Maleki, S. J., Schmitt, D. A., Galeano, M., \& Hurlburt, B. K. (2014). Comparison of the digestibility of the major peanut allergens in thermally processed peanuts and in pure form. Foods (Basel, Switzerland), 3(2), 290-303.

Meinlschmidt, P., Ueberham, E., Lehmann, J., Reineke, K., Schlüter, O., SchweiggertWeisz, U., \& Eisner, P. (2016). The effects of pulsed ultraviolet light, cold atmospheric pressure plasma, and gamma-irradiation on the immunoreactivity of soy protein isolate. Innovative Food Science \& Emerging Technologies, 38, 374-383.

Meng, X., Li, X., Wang, X., Gao, J., Yang, H., \& Chen, H. (2016). Potential allergenicity response to structural modification of irradiated bovine $\alpha$-lactalbumin. Food \& Function, 7(7), 3102-3110.

Misra, N. N., Kaur, S., Tiwari, B. K., Kaur, A., Singh, N., \& Cullen, P. J. (2015) Atmospheric pressure cold plasma (ACP) treatment of wheat flour. Food Hydrocolloids, 44, 115-121.

Misra, N. N., Schlüter, O., Cullen, P. J., \& Patrick, J. (2016). Cold plasma in food and agriculture: Fundamentals and applications.

Misra, N. N., Sullivan, C., Pankaj, S. K., Alvarez-Jubete, L., Cama, R., Jacoby, F., \& Cullen, P. J. (2014). Enhancement of oil spreadability of biscuit surface by nonthermal barrier discharge plasma. Innovative Food Science \& Emerging Technologies, 26, $456-461$.

Nesbit, J. B., Hurlburt, B. K., Schein, C. H., Cheng, H., Wei, H., \& Maleki, S. J. (2012). Ara h 1 structure is retained after roasting and is important for enhanced binding to IgE. Molecular Nutrition \& Food Research, 56(11), 1739-1747.

Nooji, J. K. (2011a). Reduction of wheat allergen potency by pulsed ultraviolet light, high hydrostactic pressure and non-thermal plasma.

Nooji, J. K. (2011b). Reduction of wheat allergen potency by pulsed ultraviolet light, high hydrostatic pressure, and non-thermal plasma. (MSc Thesis).

Pal, P., Kaur, P., Singh, N., Kaur, A., Misra, N. N., Tiwari, B. K., ... Virdi, A. S. (2016). Effect of nonthermal plasma on physico-chemical, amino acid composition, pasting and protein characteristics of short and long grain rice flour. Food Research International, 81, 50-57.

Pankaj, S. K., Bueno-Ferrer, C., Misra, N. N., O'Neill, L., Tiwari, B. K., Bourke, P., \& Cullen, P. J. (2014). Physicochemical characterization of plasma-treated sodium caseinate film. Food Research International, 66, 438-444.

Pfeifer, S., Bublin, M., Dubiela, P., Hummel, K., Wortmann, J., Hofer, G., ... HoffmannSommergruber, K. (2015). Cor a 14, the allergenic 2 S albumin from hazelnut, is highly thermostable and resistant to gastrointestinal digestion. Molecular Nutrition \& Food Research, 59(10), 2077-2086.

Piersma, S. R., Gaspari, M., Hefle, S. L., \& Koppelman, S. J. (2005). Proteolytic processing of the peanut allergen Ara h 3. Molecular Nutrition \& Food Research, 49(8), 744-755.

Poms, R. E., Capelletti, C., \& Anklam, E. (2004). Effect of roasting history and buffer composition on peanut protein extraction efficiency. Molecular Nutrition \& Food Research, 48(6), 459-464.

Sarangapani, C., Danaher, M., Tiwari, B., Lu, P., Bourke, P., \& Cullen, P. J. (2017). Efficacy and mechanistic insights into endocrine disruptor degradation using atmospheric air plasma. Chemical Engineering Journal, 326, 700-714.

Sarangapani, C., O'Toole, G., Cullen, P. J., \& Bourke, P. (2017). Atmospheric cold plasma dissipation efficiency of agrochemicals on blueberries. Innovative Food Science \& Emerging Technologies, 44, 235-241.

Sarangapani, C., Patange, A., Bourke, P., Keener, K., \& Cullen, P. J. (2018). Recent advances in the application of cold plasma technology in foods. Annual Review of Food Science and Technology, 9(1), 609-629.

Sarangapani, C., Thirumdas, R., Devi, Y., Trimukhe, A., Deshmukh, R. R., \& Annapure, U. S. (2016). Effect of low-pressure plasma on physico-chemical and functional properties of parboiled rice flour. LWT - Food Science and Technology, 69, 482-489.

Segat, A., Misra, N. N., Cullen, P. J., \& Innocente, N. (2016). Effect of atmospheric pressure cold plasma (ACP) on activity and structure of alkaline phosphatase. Food and Bioproducts Processing, 98, 181-188.

Segat, A., Misra, N. N., Fabbro, A., Buchini, F., Lippe, G., Cullen, P. J., \& Innocente, N. (2014). Effects of ozone processing on chemical, structural and functional properties of whey protein isolate. Food Research International, 66, 365-372.

Shriver, S., Yang, W., Chung, S.-Y., \& Percival, S. (2011). Pulsed ultraviolet light reduces immunoglobulin E binding to Atlantic white shrimp (Litopenaeus setiferus) extract. International Journal of Environmental Research and Public Health, 8(7), 2569-2583.

Shriver, S. K. (2011). Effect of selected nonthermal processing methods on the allergen 
reactivity of Atlantic white shrimp (Litopenaeus setiferus). MSc thesisUniversity of Florida.

Studier, F. W. (2005). Protein production by auto-induction in high-density shaking cultures. Surowsky, B., Fischer, A., Schlueter, O., \& Knorr, D. (2013). Cold plasma effects on enzyme activity in a model food system. Innovative Food Science \& Emerging Technologies, $19,146-152$.

Takai, E., Kitamura, T., Kuwabara, J., Ikawa, S., Yoshizawa, S., Shiraki, K., ... Kitano, K. (2014). Chemical modification of amino acids by atmospheric-pressure cold plasma in aqueous solution. Journal of Physics D: Applied Physics, 47(28), 285403.

Tammineedi, C. V. R. K., Choudhary, R., Perez-Alvarado, G. C., \& Watson, D. G. (2013). Determining the effect of UV-C, high intensity ultrasound and nonthermal atmospheric plasma treatments on reducing the allergenicity of $\alpha$-casein and whey proteins. LWT - Food Science and Technology, 54(1), 35-41.

Thirumdas, R., Sarangapani, C., \& Annapure, U. S. (2015). Cold plasma: A novel nonthermal technology for food processing. Food Biophysics, 10(1), 1-11.

Uzun, H., Ibanoglu, E., Catal, H., \& Ibanoglu, S. (2012). Effects of ozone on functional properties of proteins. Food Chemistry, 134(2), 647-654.

van Boxtel, E. L., van Beers, M. M. C., Koppelman, S. J., van den Broek, L. A. M., \& Gruppen, H. (2006). Allergen Ara h 1 occurs in peanuts as a large oligomer rather than as a trimer. Journal of Agricultural and Food Chemistry, 54(19), 7180-7186.

Vanga, S. K., Singh, A., \& Raghavan, V. (2017). Review of conventional and novel food processing methods on food allergens. Critical Reviews in Food Science and Nutrition, 57(10), 2077-2094.

Vissers, Y. M., Iwan, M., Adel-Patient, K., Stahl Skov, P., Rigby, N. M., Johnson, P. E., ... Wichers, H. J. (2011). Effect of roasting on the allergenicity of major peanut allergens Ara h 1 and Ara h 2/6: The necessity of degranulation assays. Clinical \& Experimental Allergy, 41(11), 1631-1642.

Wu, Y., Liang, Y., Wei, K., Li, W., Yao, M., \& Zhang, J. (2014). Rapid allergen inactivation using atmospheric pressure cold plasma. Environmental Science \& Technology, 48(5), 2901-2909.

Zhenxing, L., Hong, L., Limin, C., \& Jamil, K. (2007). The influence of gamma irradiation on the allergenicity of shrimp (Penaeus vannamei). Journal of Food Engineering, 79(3), 945-949.

Zhuang, Y., \& Dreskin, S. C. (2013). Redefining the major peanut allergens. Immunologic Research, 55(1-3), 125-134.

Ziuzina, D., Patil, S., Cullen, P. J., Keener, K. M., \& Bourke, P. (2014). Atmospheric cold plasma inactivation of Escherichia coli, Salmonella enterica serovar Typhimurium and Listeria monocytogenes inoculated on fresh produce. Food Microbiology, 42, 109-116. 